\title{
Reduksi Parameter Quality-Of-Service Menggunakan Rough-Set-Theory Dalam Simulasi Routing Algoritma Dijkstra
}

\author{
Gede Saindra S.*1, Reza Pulungan ${ }^{2}$ \\ ${ }^{1}$ Program Studi S2/S3 Ilkom, FMIPA, UGM, Yogyakarta \\ ${ }^{2}$ Jurusan Ilmu Komputer dan Elektronika, FMIPA UGM, Yogyakarta \\ e-mail: *1'gsaindras @gmail.com, ${ }^{2}$ pulungan@ugm.ac.id
}

\begin{abstract}
Abstrak
Proses pemilihan jalur/rute terbaik dalam proses routing melibatkan bobot-bobot yang terbentuk dalam topologi jaringan. Terdapat banyak parameter yang menunjang munculnya bobot tersebut. Kesalahan dalam pemilihan parameter dapat mengganggu proses kumunikas $i$ data yang terlihat pada communication-overhead (CO) yang muncul dalam jaringan. Proses reduksi parameter dalam teori Rough Set dapat memilih parameter mana yang dianggap penting sesuai dengan nilai quality of service. Sehing ga dari sekian banyak parameter, akan terpilih parameter yang akan dijadikan bobot dalam topologi. Hal ini akan mengurangi beban CO yang akan mengoptimalkan proses routing dalam jaringan.
\end{abstract}

Kata kunci-Quality of Service, reduksi parameter, teori rough set, routing, algoritma Dijkstra

\begin{abstract}
Path selection process/best route in the routing process involves weights that are formed in the network topology. There are many parameters that support the emergence of these weights. Errors in the selection process parameters can interfere with communication data seen in communication-overhead (CO) which appears in the network. Reduction process on Rough Set theory can select the parameters which are considered important parameters in accordance with the quality of service $(Q o S)$. So of the many parameters, will be selected parameters to be used as weights in the topology. This will reduce the burden of CO that will optimize the process of routing in the network.
\end{abstract}

Keywords-Quality of Service, parameter's reduction, rough set theory, routing, Dijkstra algorithm

\section{PENDAHULUAN}

Kurose dan Ross [1] menyatakan bahwa algoritma routing memiliki tujuan menemukan jalur yang "baik" dari sumber ke tujuan. Pengertian "baik" dalam hal ini adalah memiliki cost terkecil. Algoritma routing yang populer saat ini adalah algoritma Dijkstra dan algoritma Bellman-Ford. Mereka menggunakan satu ukuran untuk menentukan cost dari sebuah jalur yaitu nilai jarak dari satu link ke link lainnya dalam pencarian jalur yang dapat diasumsikan bahwa jarak terpendek adalah jalur terbaik. Hal ini jika menggunakan satu parameter mungkin tidak akan menimbulkan masalah. Masalah terjadi ketika kita menggunakan lebih dari satu parameter seperti parameter-parameter yang terdapat di dalam Quality of Service (QoS ) di mana kita akan berasumsi lain bahwa jarak terpendek belum tentu jalur terbaik. Sakr [2] menyatakan bahwa parameter QoS dalam suatu jalur internet dapat berupa ketersediaan bandwidth, propagation

Received February 27 $7^{\text {th }}, 2012 ;$ Revised March 15 $5^{\text {th }}, 2012$; Accepted June $7^{\text {th }}, 2012$ 
delay, link jitter, rasio terhadap bit error, dan kemungkinan melakukan hubungan (connection possibility).

Router adalah perangkat keras yang bertugas mengatur lalu lintas data dalam jaringan internet. Komunikasi antar router diatur oleh routing protocol yang diimplementasikan di dalam topologinya masing-masing baik itu topologi eksternal maupun internal. Dalam Cisco-Systems [3], ada tiga bagian dalam protokol routing berupa struktur data, algoritma, dan routing protocol messages. Dari ketiga elemen tersebut yang sangat mempengaruhi kinerja dalam routing adalah algoritma yang diimplementasikan di dalam routing protocol tersebut. Algoritma yang umum digunakan dalam routing protocol seperti Routing Information Protocol (RIP), Open Shorthest Path First (OSPF) dan Internet Gateway Routing Protocol (IGRP) adalah algoritma Dijkstra dan algoritma Bellman-Ford. Meskipun kedua algoritma ini sama-sama menyelesaikan masalah dalam ranah single-source shortest paths atau sama-sama menggunakan prinsip Shorthest Path First (SPF), namun kedua algoritma tersebut memiliki perbedaan dalam hal kompleksitas. Dijkstra memiliki kompleksitas yang lebih kecil dibandingkan dengan Bellman-Ford.

Kemampuan suatu algoritma di dalam menyelesaikan masalah dapat diukur dengan melihat keoptimalan langkah-langkah penyelesaian masalah yang diimplementasikan di dalamnya karena dengan adanya langkah-langkah yang lebih optimal, maka kecenderungan suatu algoritma untuk menyelesaikan masalah akan lebih besar. Dalam [4], Goldberg berpendapat bahwa metode optimasi adalah memilih solusi yang terbaik/ideal dalam kumpulan solusi yang besar di mana solusi tersebut masih berada dalam batasan yang legal. Dalam perencanaan jaringan, solusi yang ideal dan legal dapat berupa topologi, struktur jalur, atau rincian kapasitas pekerjaan dengan biaya yang minimum.

Khattab [5] menyatakan bahwa SPF memiliki sifat not-scalable yang artinya ukuran/metric tidak dapat diubah. Jadi ukuran-ukuran yang akan dimasukkan dalam perhitungan pencarian jalur, tidak dapat direpresentasikan dalam berbagai ukuran. Sifat yang non-scalable mengakibatkan peningkatan Communication-Overhead (CO) dalam jaringan berskala besar. Clement [6] menyatakan bahwa definisi CO secara umum adalah proporsi waktu yang diperlukan untuk berkomunikasi antar pelaku komunikasi dengan tidak melakukan kerja yang produktif. Secara teknis CO dapat diartikan sebagai komunikasi yang dilakukan dalam kombinasi yang berlebih. Kombinasi yang dimaksud secara tidak langsung mengacu pada waktu komputasi, memori, bandwidth, atau sumber daya lainnya yang dibutuhkan untuk mencapai tujuan tertentu atau dapat juga kombinasi yang dimaksud adalah parameter QoS itu sendiri. Jadi semakin besar CO yang didapat dalam suatu jaringan internet, maka waktu yang diperlukan untuk berkomunikasi semakin besar namun pekerjaan yang diselesaikan minimal. Inilah yang membuat algoritma SPF seperti Dijkstra menjadi kurang optimal.

Dalam [2], teknik reduksi menggunakan teori Rough Set dapat diimplementasikan dalam pereduksian parameter QoS. Banyaknya parameter QoS dikelompokkan berdasarkan jenisnya sehingga menjadi 5 parameter utama. Parameter tersebut adalah bandwidth, delay, jitter, error, dan connection. Kelima parameter tersebut direduksi sehingga menjadi parameter yang lebih sedikit sesuai dengan kondisi dalam jaringan pada setiap linknya. Hal ini diharapkan akan menghasilkan $\mathrm{CO}$ yang rendah sehingga menghasilkan kualitas link pada jaringan yang lebih baik.

Penelitian ini menggunakan teori Rough Set (RS) dalam reduksi parameter QoS untuk memperbaiki kinerja algoritma yang lama. Reduksi dilakukan pada parameter QoS di mana tidak setiap saat kesemua parameter QoS diikutsertakan dalam perhitungan. Hal ini menyebabkan beban komputasi bertambah. Alangkah baiknya jika dilakukan seleksi dengan cara mengurangi (reducing) parameter yang dianggap memiliki kemiripan. Hal ini dapat dilakukan menggunakan RS di mana akan tercipta suatu tabel keputusan yang baru yang berisikan parameter terpilih yang nantinya akan digunakan dalam perhitungan pencarian jalur terbaik. Di sisi lain, dengan langkah ini, kita sudah mengurangi beban CO di atas. Algoritma ini

IJCCS Vol. 6, No. 1, January 2012 : $79-90$ 
akan bersifat scalable di mana perhitungan routing dapat menggunakan satu metrik atau lebih.

Komorowski [7], menyatakan teori RS merupakan suatu teori di mana teori tersebut dapat mengklasifikasikan sifat suatu objek terhadapt atribut-atributnya yang dalam penelitian ini objek direpresentasikan oleh link yang terbentuk dalam topologi jaringan dan atribut direpresentasikan oleh parameter QoS. Teori ini dapat memperlihatkan unsur indiscernibility suatu link berdasarkan parameter-parameter yang melekat pada link tersebut. Tujuan RS adalah untuk mengenali ketidakpastian klasifikasi dalam suatu link, dan pada penelitian ini tujuan akhir RS adalah membedakan link satu dengan yang lainnya yang kemudian mereduksi parameterparameter yang terkandung didalamnya di mana dalam hal ini parameter yang dimaksud adalah parameter QoS.

\section{METODE PENELITIAN}

Metode penelitian yang di gunakan penelitian meliputi tahap-tahap sebagai berikut.

\section{$2.1 \quad$ Studi Kepustakaan}

Pelaksanaan penelitian menggunakan studi literatur dari berbagai bahan dan sumber literatur seperti beberapa buku teks, jurnal internasional, dan beberapa karya ilmiah lainnya tentang metode reduksi dan optimasi khususnya dalam ranah teori RS dan algoritma Dijkstra dalam permasalahan routing di dalam jaringan komputer.

\subsection{Analisis dan Perancangan Sistem}

Menganalisa kasus-kasus dalam studi literatur dan sumber literatur sehingga menemukan suatu cara yang tepat dalam proses routing. Dari berbagai analisis tersebut, dibuatlah suatu rancangan sistem reduksi parameter berupa metode dengan melibatkan teori RS dan algoritma Dijkstra dalam penentuan jalur utama dan jalur alternatif.

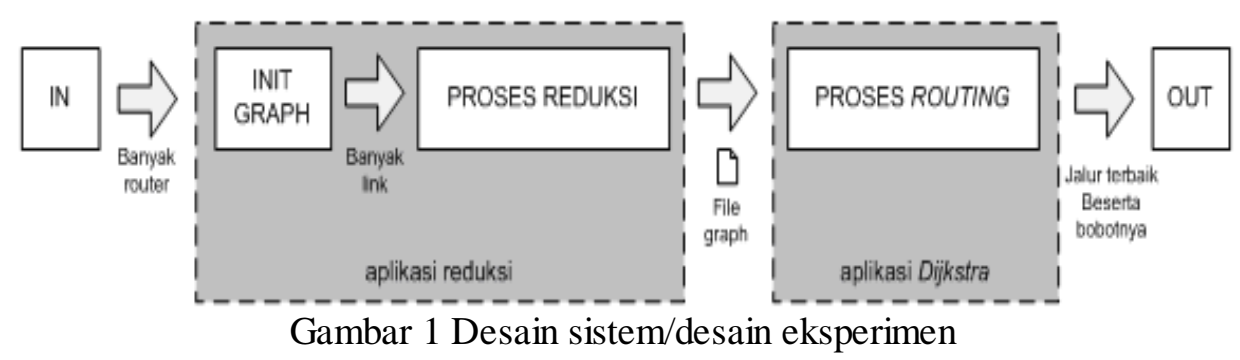

Teknik reduksi pada teori Rough Set menggunakan teknik simplifikasi dalam aljabar boolean seperti penggunaan hukum absorpsi dan distributive. Teknik reduksi inilah yang akan dipakai dalam proses reduksi parameter QoS.

\subsection{Implementasi}

Pada tahap ini dilakukan pembuatan prototype perangkat lunak sesuai dengan analisis dan perancangan sistem yang dilakukan.

\subsection{Pengujian}

Pada tahap ini dilakukan pengujian prototype perangkat lunak yang telah dibuat dari hasil penelitian untuk membandingkan hasil yang diperoleh menggunakan metode Dijkstra berparameter tidak tereduksi dengan hasil yang diperoleh menggunakan metode Dijkstra dengan parameter tereduksi dalam penentuan jalur terbaik. 


\section{HASIL DAN PEMBAHASAN}

Implementasi sistem dalam penelitian menghasilkan sebuah sistem untuk mereduksi parameter QoS dengan teori Rough Set dalam simulasi routing pada jaringan komputer menggunakan algoritma Dijkstra. Percobaan dilakukan dengan membandingkan antara hasil routing menggunakan parameter tereduksi dengan hasil routing menggunakan parameter tidak tereduksi.

Dalam penelitian ini, dilakukan percobaan dengan menggunakan banyak router dalam graf secara beragam. Mulai dari 5, 10, 25, 50, 100, 500, 1000, 5000 sampai 10000 router. Masing-masing percobaan banyak router, diuji kembali sebanyak 10 kali percobaan sehingga akan menghasilkan tabel perbandingan antara hasil routing menggunakan parameter tereduksi dengan hasil routing menggunakan parameter tidak tereduksi. Terdapat banyak data dalam tabel percobaan seperti pada Tabel 1. Data yang diteliti adalah bobot terhadap jalur yang diuji antara menggunakan proses reduksi (reduced) dengan tidak menggunakan proses reduksi (unreduced). Adapun masukan router sumber dengan router tujuan dibuat secara acak. Selain melakukan uji coba pada bobot, dilakukan juga uji coba komputasi atau waktu proses antara reduksi dengan tidak. Beberapa atribut tambahan dalam Tabel 6.1 adalah berupa beban communicationoverhead dan parameter yang terpilih atau parameter hasil reduksi untuk setiap percobaan. Tabel 6.1 merupakan hasil untuk percobaan menggunakan 5 router di mana data graf dan bobot untuk percobaan menggunakan 5 router dapat dilihat pada Lampiran B data nomor 1 sampai dengan data nomor 20.

Tabel 1 sampai dengan Tabel 9 merupakan Tabel yang memiliki makna yang sama dalam setiap kolomnya. Kolom pertama merupakan banyak percobaan yang dilakukan. Kolom ke-2 merupakan banyak router dan banyak link yang diuji. Kolom ke-3 merupakan kolom rute, bobot, dan waktu (T) yang diperlukan untuk mendapatkan rute dalam mili detik dari router sumber ke router tujuan menggunakan parameter tidak tereduksi. Kolom ke-4 merupakan kolom rute, bobot, dan waktu $(\mathrm{T})$ yang diperlukan untuk mendapatkan rute dalam mili detik dari router sumber ke router tujuan menggunakan parameter tereduksi. Kolom ke-5 adalah beban communication-overhead yang didapat dari pengurangan bobot tidak tereduksi dengan bobot tereduksi. Kolom ke-6 merupakan parameter QoS yang digunakan untuk perhitungan routing menggunakan parameter tereduksi.

Waktu (T) dalam Tabel 1 sampai dengan Tabel 9 merupakan komputasi yang dihasilkan dalam proses mendapatkan rute dari router sumber ke router tujuan. Dalam proses tersebut, bisa juga terdapat proses reduksi (kalau menggunakan reduksi), bisa juga tanpa proses reduksi. Jadi waktu yang digunakan untuk mereduksi sudah termasuk di dalamnya. Nilai 0 dalam kolom $\mathrm{T}$ menandakan proses berlangsung dalam hitungan mikro detik. Hal ini dikarenakan bahasa pemrograman yang digunakan tidak mampu menghitung waktu pemrosesan dalam satuan mikro detik.

Tabel 1 Hasil percobaan menggunakan 5 router

\begin{tabular}{|c|c|c|c|c|c|c|c|c|c|}
\hline \multirow{2}{*}{$\begin{array}{c}\text { Percobaan } \\
\text { Ke }\end{array}$} & \multirow{2}{*}{\begin{tabular}{|c|} 
Banyak \\
$\mathrm{R} \mathrm{L}^{* * *}$ \\
\end{tabular}} & \multicolumn{3}{|c|}{ UNREEDUCED } & \multicolumn{3}{|c|}{ REDUCED } & \multirow{2}{*}{$\operatorname{co}^{* *}$} & \multirow{2}{*}{$\begin{array}{l}\text { PRMTR } \\
\text { QoS }\end{array}$} \\
\hline & & ROUTE & BOBOT & $\mathrm{T}$ & ROUTE & ВОВОТ & $\mathrm{T}$ & & \\
\hline 1 & 57 & $1-2-5$ & 453 & 0 & $1-4-5$ & 207 & 0 & 246 & $\mathrm{EC}$ \\
\hline 2 & 57 & $1-4-5$ & 422 & 0 & $1-3-4-5$ & 132 & 0 & 290 & $\mathrm{EC}$ \\
\hline 3 & $5 \pi$ & $1-3-5$ & 456 & 0 & $1-4-5$ & 64 & 0 & 392 & $E$ \\
\hline 4 & $5 / 9$ & $1-3-5$ & 436 & 0 & $1-3-5$ & 48 & 0 & 388 & $E$ \\
\hline 5 & $5 / 6$ & $2-3-4$ & 505 & 0 & $2-3-4$ & 137 & 0 & 368 & $\mathrm{C}$ \\
\hline 6 & 57 & $1-4-3$ & 441 & 0 & $1-5-3$ & 103 & 0 & 338 & $\mathrm{D}$ \\
\hline 7 & $5 \pi$ & $1-4-5$ & 467 & 0 & $1-2-5$ & 204 & 0 & 263 & $D C$ \\
\hline 8 & 5.8 & $2-5-3$ & 449 & 0 & $2-5-3$ & 99 & 0 & 350 & J \\
\hline 9 & 5.6 & $1-3-4$ & 511 & 0 & $1-2-4$ & 182 & 0 & 329 & $\mathrm{JC}$ \\
\hline 10 & $5 / 8$ & $2-5-3$ & 453 & 0 & $2-4-3$ & 93 & 0 & 360 & $E$ \\
\hline \multicolumn{3}{|c|}{ AVG } & 459.3 & 0 & & 126.9 & 0 & 332.4 & \\
\hline \multicolumn{3}{|c|}{ STDDEV } & 27.0 & 0 & & 53.1 & 0 & & \\
\hline
\end{tabular}

IJCCS Vol. 6, No. 1, January 2012 : $79-90$ 
Tabel 2 merupakan hasil untuk percobaan menggunakan 10 router di mana data dari percobaan ini dapat diunduh di alamat.

Tabel 2 Hasil percobaan menggunakan 10 router

\begin{tabular}{|c|c|c|c|c|c|c|c|c|c|}
\hline \multirow{2}{*}{$\begin{array}{c}\text { Percobaan } \\
\text { Ke }\end{array}$} & \multirow{2}{*}{\begin{tabular}{|c|} 
Banyak \\
$\mathrm{R} \Omega^{* * *}$
\end{tabular}} & \multicolumn{3}{|c|}{ UNREDUCED } & \multicolumn{3}{|c|}{ REDUCED } & \multirow{2}{*}{$\mathrm{CO}^{* *}$} & \multirow{2}{*}{$\begin{array}{c}\text { PRMTR } \\
\text { QoS }\end{array}$} \\
\hline & & ROUTE & BOBOT & $T$ & ROUTE & BOBOT & $T$ & & \\
\hline 1 & $10 / 20$ & $3-7-9$ & 581 & 0 & $3-6-8-9$ & 209 & 0 & 372 & $D E$ \\
\hline 2 & $10 / 19$ & 2-6-9-10 & 654 & 0 & $2-7-8-10$ & 186 & 0 & 468 & $\mathrm{BE}$ \\
\hline 3 & $10 / 18$ & $2-9-10$ & 482 & 0 & $2-9$ & 97 & 0 & 385 & $D C$ \\
\hline 4 & $10 / 20$ & $1-2-9-10$ & 552 & 0 & $1-8-10$ & 97 & 0 & 455 & $\mathrm{~J}$ \\
\hline 5 & $10 / 21$ & $2-3-1-4$ & 680 & 0 & $2-3-1-4$ & 201 & 0 & 479 & $D E$ \\
\hline 6 & $10 / 21$ & $2-4-5-3$ & 551 & 0 & $2-7-8-5-3$ & 216 & 0 & 335 & $\mathrm{JC}$ \\
\hline 7 & $10 / 21$ & $1-7-9-4$ & 629 & 0 & $1-7-9-4$ & 269 & 0 & 360 & $J C$ \\
\hline 8 & $10 / 21$ & $1-5-4$ & 487 & 0 & $1-5-4$ & 150 & 0 & 337 & $8 \mathrm{~J}$ \\
\hline 9 & $10 / 19$ & $1-7-5$ & 483 & 0 & $1-10-9-5$ & 118 & 0 & 365 & B \\
\hline 10 & $10 / 21$ & $1-8-10$ & 516 & 0 & 1-8-9-10 & 44 & 0 & 472 & C \\
\hline \multicolumn{3}{|c|}{ AVG } & 561.5 & $\mathbf{0}$ & & $\begin{array}{l}158.7 \\
\end{array}$ & 0 & 402.8 & \\
\hline \multicolumn{3}{|c|}{ STDDEV } & 69.2 & o & & 65.6 & 0 & & \\
\hline
\end{tabular}

Tabel 3 merupakan hasil untuk percobaan menggunakan 25 router di mana data dari percobaan ini dapat diunduh di alamat.

Tabel 3 Hasil percobaan menggunakan 25 router

\begin{tabular}{|c|c|c|c|c|c|c|c|c|c|}
\hline \multirow{2}{*}{$\begin{array}{c}\text { Percobaan } \\
\text { Ke }\end{array}$} & \multirow{2}{*}{\begin{tabular}{|l|} 
Banyak \\
$\mathrm{R} \Omega$ *** \\
\end{tabular}} & \multicolumn{3}{|c|}{ UNREDUCED } & \multicolumn{3}{|c|}{ REDUCED } & \multirow{2}{*}{$\mathrm{CO}^{* *}$} & \multirow{2}{*}{$\begin{array}{c}\text { PRMTR } \\
\text { QOS }\end{array}$} \\
\hline & & ROUTE & BOBOT & $\mathrm{T}$ & ROUTE & BOBOT & $\mathrm{T}$ & & \\
\hline 1 & 25,63 & 1-20-16-12 & \begin{tabular}{|l|}
715 \\
\end{tabular} & 0 & 1-20-19-17-3-8-12 & 252 & 0 & 463 & $\mathrm{JE}$ \\
\hline 2 & 25,61 & $1-10-15-12$ & 701 & 0 & 1-10-18-24-25-8-12 & 228 & 0 & 473 & $\mathrm{DE}$ \\
\hline 3 & $25 / 59$ & 1-22-25-20-21-12 & 956 & 0 & \begin{tabular}{|l|}
$1-4-18-21-12$ \\
\end{tabular} & 314 & 0 & 642 & $\mathrm{DE}$ \\
\hline 4 & 25,62 & 1-7-13-22 & 615 & 0 & $1-7-19-20-22$ & 263 & 0 & 352 & $\mathrm{DE}$ \\
\hline 5 & 25,64 & 1-24-19-13 & 707 & 0 & $1-21-5-7-13$ & 233 & 0 & 474 & $\mathrm{JE}$ \\
\hline 6 & 25,66 & 1-7-13-18 & 577 & 0 & 1-9-18 & 238 & 0 & 339 & DJ \\
\hline 7 & 25,61 & 1-5-20-23 & 717 & 0 & $1-10-25-23$ & 298 & 0 & 419 & $\mathrm{EC}$ \\
\hline 8 & 25,63 & $1-10-24-25$ & 732 & 0 & $1-21-23-25$ & 279 & 0 & 453 & $D C$ \\
\hline 9 & 25,62 & $1-15-23-18$ & 585 & 0 & 1-24-25-22-18 & 195 & 0 & 390 & DJ \\
\hline 10 & 25,62 & 1-22-16-12 & 602 & 0 & $1-18-16-12$ & 218 & 0 & 384 & $\mathrm{DB}$ \\
\hline \multicolumn{3}{|c|}{ AVG } & 690.7 & $\mathbf{0}$ & & 251.8 & $\mathbf{0}$ & 438.9 & \\
\hline \multicolumn{3}{|c|}{ STDDEV } & 105.6 & $\mathbf{0}$ & & 35.1 & $\mathbf{0}$ & & \\
\hline
\end{tabular}

Tabel 6.4 merupakan hasil untuk percobaan menggunakan 50 router di mana data dari percobaan ini dapat diunduh di alamat.

Tabel 4 Hasil percobaan menggunakan 50 router

\begin{tabular}{|c|c|c|c|c|c|c|c|c|c|}
\hline \multirow{2}{*}{\begin{tabular}{|c|} 
Percobaan \\
Ke
\end{tabular}} & \multirow{2}{*}{$\begin{array}{l}\text { Banyak } \\
\text { RL"*t* }\end{array}$} & \multicolumn{3}{|c|}{ UNREDUCED } & \multicolumn{3}{|c|}{ REDUCED } & \multirow{2}{*}{$\mathrm{CO}^{* *}$} & \multirow{2}{*}{$\begin{array}{c}\text { PRMTR } \\
\text { QoS }\end{array}$} \\
\hline & & ROUTE & BOBOT & $T$ & ROUTE & BOBOT & T & & \\
\hline 1 & $50 / 133$ & $1-12-20-50$ & 697 & 0 & $1-2-31-34-42-50$ & 328 & 32 & 369 & DJ \\
\hline 2 & $50 / 134$ & $1-10-5-16-40$ & 604 & 0 & $1-10-42-40$ & 389 & 30 & 215 & $\mathrm{BJC}$ \\
\hline 3 & $50 / 139$ & 1-33-50-47-40 & 654 & 0 & 1-18-24-50-47-40 & 176 & 31 & 478 & $D C$ \\
\hline 4 & $50 / 133$ & $1-31-34-25$ & 631 & 0 & $1-23-50-47-25$ & 230 & 31 & 401 & $\mathrm{JC}$ \\
\hline 5 & $50 / 136$ & 1-35-18-36-30 & 770 & 0 & $1-47-37-42-30$ & 424 & 30 & 346 & $\mathrm{BJC}$ \\
\hline 6 & $50 / 137$ & $1-22-34-16-5$ & 1117 & 0 & $1-13-15-38-37-5$ & 605 & 46 & 512 & DJE \\
\hline 7 & $50 / 132$ & $1-25-23-5$ & 770 & 0 & $1-48-46-20-5$ & 259 & 32 & 511 & $\mathrm{DB}$ \\
\hline 8 & $50 / 135$ & $1-20-28-19-5$ & 837 & 0 & $1-11-22-12-37-19-5$ & 359 & 30 & 478 & DJ \\
\hline 9 & $50 / 138$ & $1-10-18-40$ & 725 & 0 & $1-11-33-50-40$ & 265 & 32 & 460 & $D E$ \\
\hline 10 & $50 / 136$ & $1-36-42-40$ & 741 & 0 & $1-36-25-6-40$ & 265 & 47 & 476 & $\mathrm{DB}$ \\
\hline \multicolumn{3}{|c|}{ AVG } & 754.6 & $\mathbf{0}$ & & 330.0 & 34.1 & 424.6 & \\
\hline \multicolumn{3}{|c|}{ STDDEV } & 138.2 & $\mathbf{0}$ & & 116.6 & 6.3 & & \\
\hline
\end{tabular}

Tabel 5 merupakan hasil untuk percobaan menggunakan 100 router di mana data dari percobaan ini dapat diunduh di alamat http://goo.gl/UBke2. 
Tabel 5 Hasil percobaan menggunakan 100 router

\begin{tabular}{|c|c|c|c|c|c|c|c|c|c|}
\hline \multirow{2}{*}{$\begin{array}{c}\text { Percobaan } \\
\text { Ke }\end{array}$} & \multirow{2}{*}{$\begin{array}{c}\text { Banyak } \\
\mathrm{R} \Lambda^{* * *} \\
\end{array}$} & \multicolumn{3}{|c|}{ UNRREDUCED } & \multicolumn{3}{|c|}{ REDUCED } & \multirow{2}{*}{$C \mathrm{CO}^{* *}$} & \multirow{2}{*}{$\begin{array}{c}\text { PRMTR } \\
\text { QOS } \\
\end{array}$} \\
\hline & & ROUTE & BOBOT & $T$ & ROUTE & ВOBOT & $\mathrm{T}$ & & \\
\hline 1 & $100 / 275$ & 1-12-96-77-90 & 8480 & 0 & $1-29-34-42-90$ & 2763 & 125 & 5717 & $\mathrm{BE}$ \\
\hline 2 & $100 / 283$ & 1-56-99-90 & 6819 & 0 & $1-52-65-90$ & 2406 & 124 & 4413 & BJ \\
\hline 3 & $100 / 283$ & 1-50-61-90 & 4821 & 0 & 1-44-78-90 & 1844 & 124 & 2977 & $E C$ \\
\hline 4 & $100 / 286$ & $1-23-32-50-80$ & 9115 & 0 & $1-56-62-99-80$ & 2683 & 124 & 6432 & $B \mathrm{~J}$ \\
\hline 5 & $100 / 283$ & |1-27-64-67 & 8484 & 0 & 1-27-70-79-82-67 & 2706 & 124 & 5778 & B J \\
\hline 6 & $100 / 285$ & 1-48-43-35-28 & 10298 & 0 & 1-94-81-18-35-28 & 3672 & 139 & 6626 & $\mathrm{JE}$ \\
\hline 7 & $100 / 284$ & $1-71-91-100-28$ & 9622 & 0 & $1-50-96-100-28$ & 3700 & 124 & 5922 & $\mathrm{JE}$ \\
\hline 8 & $100 / 283$ & 1-17-55-64-28 & 9613 & 0 & 1-41-85-82-94-28 & 3581 & 124 & 6032 & $\mathrm{BC}$ \\
\hline 9 & $100 / 284$ & 1-18-44-42-28 & 8768 & 0 & $1-18-75-74-59-93-28$ & 3162 & 139 & 5606 & EC \\
\hline 10 & $100 / 281$ & 1-29-37-81-67 & 9012 & 0 & 1-29-91-92-44-67 & 2772 & 124 & 6240 & $\mathrm{JE}$ \\
\hline \multicolumn{3}{|c|}{ AVG } & 8503.2 & $\mathbf{0}$ & & \begin{tabular}{|l|l|}
2928.9 \\
\end{tabular} & 127.1 & 5574.3 & \\
\hline \multicolumn{3}{|c|}{ STDDEV } & 1510.1 & $\mathbf{0}$ & & 569.1 & 6.0 & & \\
\hline
\end{tabular}

Tabel 6 merupakan hasil untuk percobaan menggunakan 500 router di mana data dari percobaan ini dapat diunduh di alamat http://goo.gl/jaljg.

Tabel 6 Hasil percobaan menggunakan 500 router

\begin{tabular}{|c|c|c|c|c|c|c|c|c|c|}
\hline Percobaan & Banyak & UNREDUCEI & & & REDUCED & & & & PRMTR \\
\hline $\mathrm{Ke}$ & $\mathrm{R} \mathrm{L}^{* * *}$ & ROUTE & BOBOT & $\mathrm{T}$ & ROUTE & BOBOT & T & & $\cos$ \\
\hline 1 & $500 / 476$ & $1-309-478-418-76-100$ & 11266 & 0 & 1-309-478-450-443-440-280-100 & 6779 & 3358 & 4487 & DJC \\
\hline 2 & $500 / 474$ & $1-30-48-477-493-491-100$ & 11645 & 0 & $1-30-351-50-416-483-496-493-491-100$ & 3916 & 3391 & 7729 & $\mathrm{JE}$ \\
\hline 3 & $500 / 487$ & $1-462-184-278-100$ & 11572 & 0 & $1-266-149-466-278-100$ & 7688 & 3421 & 3884 & $\mathrm{DB}$ \\
\hline 4 & $500 / 477$ & 1-269-267-112-250-235 & 10815 & 0 & 1-69-313-472-495-250-235 & 4014 & 3890 & 6801 & $\mathrm{BC}$ \\
\hline 5 & $500 / 479$ & 1-279-489-488-230-235 & 10018 & 0 & 1-157-450-473-427-235 & 6107 & 3374 & 3911 & DEC \\
\hline 6 & $500 / 481$ & 1-273-201-416-235 & 9314 & 0 & $1-412-113-360-235$ & 2768 & 3391 & 6546 & $\mathrm{JEC}$ \\
\hline 7 & $500 / 484$ & 1-376-488-367-235 & 10738 & 0 & $1-376-351-476-344-235$ & 5734 & 3405 & 5004 & $B E$ \\
\hline 8 & $500 / 480$ & $1-246-390-315-235$ & 7924 & 0 & 1-277-396-51-465-491-235 & 3734 & 3374 & 4190 & $\mathrm{JE}$ \\
\hline 9 & $500 / 474$ & $1-306-429-428-123$ & 10217 & 0 & 1-306-374-334-181-129-123 & 6830 & 3374 & 3387 & JEC \\
\hline 10 & $500 / 478$ & 1-203-495-487-191-123 & 10809 & 0 & 1-203-495-378-377-379-123 & 3864 & 3406 & 6945 & DBE \\
\hline & & IVG & 10431.8 & 0.0 & & 5143.4 & 3438.4 & 5288.4 & \\
\hline & & TDDEV & 1077.3 & 0.0 & & 1591.2 & 151.6 & & \\
\hline
\end{tabular}

Tabel 7 merupakan hasil untuk percobaan menggunakan 1000 router di mana data dari percobaan ini dapat diunduh di alamat http://goo.gl/C9Lj7.

Tabel 7 Hasil percobaan menggunakan 1000 router

\begin{tabular}{|c|c|c|c|c|c|c|c|c|c|}
\hline Percobaan & Banyak & \multicolumn{3}{|l|}{ UNREDUCED } & \multicolumn{3}{|l|}{ REDUCED } & \multirow{2}{*}{$C O^{* *}$} & \multirow{2}{*}{$\begin{array}{c}\text { PRMTR } \\
\text { OoS }\end{array}$} \\
\hline Ke & $R L^{* * *}$ & \begin{tabular}{|l|l|} 
ROUTE & \\
\end{tabular} & BOBOT & $T$ & ROUTE & BOBOT & $\mathrm{T}$ & & \\
\hline 1 & $1000 / 2972$ & $1-755-891-945-380-10$ & 10614 & 14 & 1-755-840-862-945-380-10 & 5904 & 15250 & 4710 & DJC \\
\hline 2 & $1000 / 2973$ & 1-446-998-371-772-124 & 12176 & 16 & 1-446-998-967-935-724-788-641-124 & 6999 & 15827 & 5177 & JEC \\
\hline 3 & $1000 / 2977$ & $1-941-982-890-548-128$ & 12429 & 15 & $1-674-536-777-780-566-245-128$ & 6620 & 16124 & 5809 & DEC \\
\hline 4 & $1000 / 2973$ & 1-980-855-313-9 & 10780 & 14 & $1-497-790-226-462-184-9$ & 6354 & 15703 & 4426 & DJC \\
\hline 5 & $1000 / 2970$ & 1-180-917-836-803-123-90 & 13184 & 15 & 1-180-971-936-621-146-812-490-90 & 8479 & 15625 & 4705 & $\mathrm{BJE}$ \\
\hline 6 & $1000 / 2975$ & 1-122-882-794-821-761-4 & 12311 & 16 & $1-327-355-935-947-895-761-4$ & 6968 & 15360 & 5343 & $D B E$ \\
\hline 7 & $1000 / 2976$ & $1-144-904-945-931-400-4$ & 11296 & 16 & 1-144-330-967-896-379-4 & 7226 & 15765 & 4070 & $\mathrm{DEC}$ \\
\hline 8 & $1000 / 2978$ & $1-250-590-455-771-100$ & 12922 & 16 & $1-250-995-986-552-263-100$ & 7063 & 15672 & 5859 & D JC \\
\hline 9 & $1000 / 2974$ & $1-180-741-964-345-100$ & 12356 & 15 & 1-564-818-350-301-100 & 7560 & 15875 & 4796 & DJE \\
\hline 10 & $1000 / 2979$ & $1-745-824-937-612-506-178$ & 11629 & 15 & 1-745-70-742-671-612-506-178 & 6692 & 15407 & 4937 & $\mathrm{BJE}$ \\
\hline \multicolumn{3}{|r|}{ AVG } & 11969.7 & 15.2 & & 6986.5 & 15660.8 & 4983.2 & \\
\hline \multicolumn{3}{|c|}{ STDDEV } & 820.0 & 0.7 & & 664.3 & 250.2 & & \\
\hline
\end{tabular}

Tabel 8 merupakan hasil untuk percobaan menggunakan 5000 router di mana data dari percobaan ini dapat diunduh di alamat http://goo.gl/I7G38.

Tabel 8 Hasil percobaan menggunakan 5000 router

\begin{tabular}{|c|c|c|c|c|c|c|c|c|c|}
\hline \multirow{2}{*}{\begin{tabular}{|c|} 
Percobaan \\
Ke
\end{tabular}} & \multirow{2}{*}{$\begin{array}{c}\text { Banyak } \\
\mathrm{R} / * * *\end{array}$} & \multicolumn{3}{|l|}{ UNREDUCED } & \multicolumn{3}{|l|}{ REDUCED } & \multirow{2}{*}{$\cos *$} & \multirow{2}{*}{\begin{tabular}{|c|} 
PRMTR \\
QoS \\
\end{tabular}} \\
\hline & & ROUTE & $\mathrm{BOBOT}$ & $\mathrm{T}$ & ROUTE & BOBOT & $\mathrm{T}$ & & \\
\hline 1 & $5000 / 14974$ & 1-2573-4333-3172-2971-2818-2460-356 & 15600 & 356 & 1-2455-168-4428-354-625-3939-4091-3629-356 & 8507 & 52576 & 7093 & $\mathrm{BJC}$ \\
\hline 2 & $5000 / 4970$ & 1-1558-4085-4441-4446-3360-1235 & 14373 & 355 & 1-1558-4666-4742-4759-4438-1796-1235 & 7237 & 67466 & 7136 & JEC \\
\hline 3 & $5000 / 44977$ & 1-2802-4707-4880-4884-4877-4892-947-1583-45 & 14046 & 356 & $1-1666-2347-4395-3053-2300-45$ & 7544 & 80349 & 6502 & $\mathrm{BEC}$ \\
\hline 4 & $5000 / 14965$ & 1-2601-1450-4222-3988-4552-3000 & 12880 & 354 & 1-4240-2202-3153-3158-4386-4689-3000 & 7343 & 76519 & 5537 & $\mathrm{BJE}$ \\
\hline 5 & $5000 / 14972$ & $1-2207-1151-4972-4995-89-1234$ & 14892 & 356 & 1-583-4774-4938-4998-4994-3383-1234 & 9622 & 72030 & 5270 & DJE \\
\hline 6 & $5000 M 4973$ & $1-4491-4868-4627-4214-4505-1235$ & 12631 & 354 & 1-4491-2301-4410-3531-3730-2320-1235 & 8125 & 52196 & 4506 & $\mathrm{BEC}$ \\
\hline 7 & $5000 / 14971$ & $1-2618-2625-1118-4951-4739-2727-974-547$ & 14455 & 356 & 1-2503-3804-4709-4945-4942-547 & 8118 & 69901 & 6337 & $\mathrm{DBC}$ \\
\hline 8 & $5000 / 4967$ & 1-4208-498-1361-1196-1102-872 & 14967 & 354 & 1-2397-4847-4421-3868-4056-4226-1102-872 & 7817 & 80520 & 7150 & DJE \\
\hline 9 & $5000 / 14979$ & 1-3664-4471-4985-4971-4970-4236-872 & 13588 & 355 & 1-1339-4849-4974-4970-4236-872 & 6717 & 50722 & 6871 & $\mathrm{DBE}$ \\
\hline 10 & $5000 / 44971$ & $1-4056-4045-4093-4576-4819-1347-893$ & 14790 & 355 & 1-4056-4218-4402-2646-4575-4066-807-1799-893 & 7793 & 56689 & 6997 & $\mathrm{BJE}$ \\
\hline \multicolumn{3}{|r|}{ AVG } & 14222.2 & 355.1 & & 7882.3 & 65896.8 & 6339.9 & \\
\hline \multicolumn{3}{|r|}{ STDDEV } & $\mathbf{8 9 8 . 2}$ & 0.8 & & 756.5 & 11277.7 & & \\
\hline
\end{tabular}

IJCCS Vol. 6, No. 1, January 2012 : $79-90$ 
Tabel 9 merupakan hasil untuk percobaan menggunakan 10000 router di mana data dari percobaan ini dapat diunduh di alamat http://goo.gl/LCF69.

Tabel 9 Hasil percobaan menggunakan 10000 router

\begin{tabular}{|c|c|c|c|c|c|c|c|c|c|}
\hline \multirow{2}{*}{$\begin{array}{c}\text { Percobaan } \\
\text { Ke } \\
\end{array}$} & \multirow{2}{*}{$\begin{array}{l}\text { Banyak } \\
\text { RL"** }\end{array}$} & \multicolumn{3}{|l|}{ UNREDUCED } & \multicolumn{3}{|l|}{ REDUCED } & \multirow{2}{*}{$\cos ^{* *}$} & \multirow{2}{*}{$\begin{array}{c}\text { PRMTR } \\
\text { CoS }\end{array}$} \\
\hline & & ROUTE & ВОВОТ & $\mathrm{T}$ & ROUTE & BOBOT & $T$ & & \\
\hline 1 & $10000 / 29975$ & $1-5745-6754-6821-6498-6667-23$ & 15217 & 713 & 1-2588-6904-6894-6998-6992-6799-6667-23 & 8676 & 391798 & 6541 & $\mathrm{BJC}$ \\
\hline 2 & $10000 / 29965$ & 1-2035-6261-6363-6921-6095-3943-23 & 14108 & 710 & $1-2035-6261-6437-6215-6551-4089-45-23$ & 8919 & 388574 & 5189 & DJE \\
\hline 3 & $10000 / 29964$ & $1-5390-5393-5560-6404-6199-32$ & 14271 & 714 & 1-6091-5908-6909-6935-6893-3771-32 & 8928 & 400018 & 5343 & $\mathrm{BEC}$ \\
\hline 4 & $10000 / 29974$ & 1-6133-6388-1341-4861-3675-2823-12 & 14506 & 712 & 1-6133-6787-6330-6153-6534-2823-12 & 8441 & 330883 & 6065 & DEJ \\
\hline 5 & $10000 / 29977$ & 1-974-6943-6819-6366-6719-5770-15 & 14777 & 712 & 1-974-6943-6737-6609-6055-1734-15 & 8480 & 392210 & 6297 & DBE \\
\hline 6 & $10000 / 29977$ & 1-6872-6996-6992-6988-6725-20 & 13098 & 715 & 1-6872-6640-6479-6582-6850-6725-20 & 7295 & 389799 & 5803 & $\mathrm{DBJ}$ \\
\hline 7 & $10000 / 29970$ & $1-4120-5090-6802-6414-5958-4559-35$ & 15355 & 712 & 1-1607-5555-4078-5478-6948-6998-6996-3869-1870-35 & 9526 & 393128 & 5829 & BJE \\
\hline 8 & $10000 / 29964$ & 1-4751-5766-6992-6987-6150-6158-832 & 14695 & 711 & 1-4751-5766-5056-6081-6626-6549-217-832 & 7602 & 425140 & 7093 & $\mathrm{BJC}$ \\
\hline 9 & $10000 / 29968$ & 1-6417-6509-6648-6104-6055-10 & 14750 & 713 & 1-6417-6870-6985-6931-6917-6055-10 & 8242 & 344220 & 6508 & DJE \\
\hline 10 & $10000 / 29972$ & 1-4503-5643-6229-3034-6357-6981-6470-100 & 14950 & 712 & 1-4503-5643-6759-6963-6981-6470-100 & 7748 & 352737 & 7202 & $\mathrm{JEC}$ \\
\hline \multicolumn{3}{|c|}{ AVG } & 14572.7 & 712.4 & & 8385.7 & 380850.7 & 6187.0 & \\
\hline \multicolumn{3}{|r|}{ STDDEV } & 611.9 & 1.4 & & 648.5 & 27381.0 & & \\
\hline
\end{tabular}

Dari percobaan tersebut, masing-masing dihitung standar deviasinya guna memperoleh perhitungan validitas perbandingan untuk grafik errornya. Adapun kolom CO diatas merupakan communication-overhead, di mana CO ini merupakan selisih antara QoS tidak tereduksi dengan QoS tereduksi. Tabel 9 merupakan hasil tabel olah data dari ke sembilan percobaan diatas terhadap bobotnya.

Tabel 10 Rata-rata dan standar deviasi terhadap bobot

\begin{tabular}{|l|c|c|c|c|c|c|c|c|}
\hline $\begin{array}{c}\text { Banyak } \\
\text { Router }\end{array}$ & \multicolumn{9}{|c|}{ UNREDUCED } & \multicolumn{4}{c|}{ REDUCED } \\
\hline 5 & 459.3 & 27.0 & 486.3 & 432.3 & 126.9 & 53.1 & 180.0 & 73.8 \\
\hline 10 & 561.5 & 69.2 & 630.7 & 492.3 & 158.7 & 65.6 & 224.3 & 93.1 \\
\hline 25 & 690.7 & 105.6 & 796.3 & 585.1 & 251.8 & 35.1 & 286.9 & 216.7 \\
\hline 50 & 754.6 & 138.2 & 892.8 & 616.4 & 330.0 & 116.6 & 446.6 & 213.4 \\
\hline 100 & 8503.2 & 1510.1 & 10013.3 & 6993.1 & 2928.9 & 569.1 & 3498.0 & 2359.8 \\
\hline 500 & 10431.8 & 1077.3 & 11509.1 & 9354.5 & 5143.4 & 1591.2 & 6734.6 & 3552.2 \\
\hline 1000 & 11969.7 & 820.0 & 12789.7 & 11149.7 & 6986.5 & 664.3 & 7650.8 & 6322.2 \\
\hline 5000 & 14222.2 & 898.2 & 15120.4 & 13324.0 & 7882.3 & 756.5 & 8638.8 & 7125.8 \\
\hline 10000 & 14572.7 & 611.9 & 15184.6 & 13960.8 & 8385.7 & 648.5 & 9034.2 & 7737.2 \\
\hline
\end{tabular}

Tabel 10 menunjukkan rata-rata, standar deviasi dan rentangan error dari setiap router dalam percobaan antara bobot hasil tereduksi dengan tidak tereduksi. Setelah mendapatkan hasil olahan data seperti diatas, maka dibuatlah sebuah grafik agar dapat memperlihatkan secara jelas error rasio yang terjadi dalam percobaan tersebut. Gambar 1 adalah grafik error yang terbentuk.

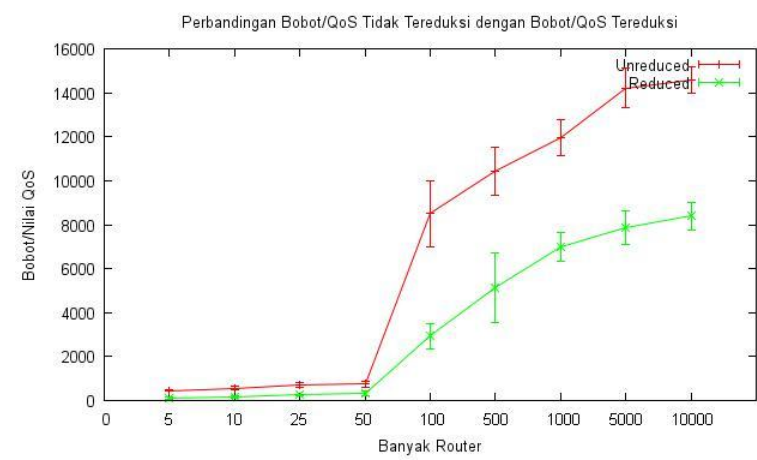

Gambar 2 Grafik error perbandingan bobot antara QoS tidak tereduksi dengan QoS tereduksi

Dari Gambar 2, terlihat dengan jelas bahwa tidak satupun data mengalami overlapping. Ini berarti, perbedaan yang ada sangat berpengaruh antara menggunakan reduksi dengan tidak menggunakan reduksi. Misalnya pada percobaan menggunakan router 10000, jarak antara error bar QoS tidak tereduksi dengan error bar QoS tereduksi sangat jauh, ini berarti perbedaaan akan sangat nampak jika router yang diaplikasikan sangat besar. 
Untuk data komputasi atau waktu prosesnya, menggunakan proses reduksi cukup memakan waktu yang lama terutama jika menggunakan router diatas 500. Perbedaan performa akan terlihat. Akan lebih cepat jika tidak menggunakan proses reduksi. Tabel 11 merupakan hasil rata-rata dan standar deviasi terhadap beban komputasi antara proses reduksi dengan tidak menggunakan proses reduksi.

Tabel 11 Rata-rata dan standar deviasi terhadap waktu proses

\begin{tabular}{|l|c|c|c|c|c|c|c|c|}
\hline Banyak & \multicolumn{3}{|c|}{ UNREDUCED } & \multicolumn{5}{c|}{ REDUCED } \\
\cline { 2 - 9 } Router & Mean & $\begin{array}{c}\text { Std } \\
\text { Dev }\end{array}$ & $\begin{array}{c}\text { Mean + } \\
\text { StdDev }\end{array}$ & $\begin{array}{c}\text { Mean - } \\
\text { StdDev }\end{array}$ & Mean & StdDev & $\begin{array}{c}\text { Mean + } \\
\text { StdDev }\end{array}$ & $\begin{array}{c}\text { Mean - } \\
\text { StdDev }\end{array}$ \\
\hline 5 & 0.0 & 0.0 & 0.0 & 0.0 & 0.0 & 0.0 & 0.0 & 0.0 \\
\hline 10 & 0.0 & 0.0 & 0.0 & 0.0 & 0.0 & 0.0 & 0.0 & 0.0 \\
\hline 25 & 0.0 & 0.0 & 0.0 & 0.0 & 0.0 & 0.0 & 0.0 & 0.0 \\
\hline 50 & 0.0 & 0.0 & 0.0 & 0.0 & 34.1 & 6.3 & 40.4 & 27.8 \\
\hline 100 & 0.0 & 0.0 & 0.0 & 0.0 & 127.1 & 6.0 & 133.1 & 121.1 \\
\hline 500 & 0.0 & 0.0 & 0.0 & 0.0 & 3438.4 & 151.6 & 3590.0 & 3286.8 \\
\hline 1000 & 15.2 & 0.7 & 15.9 & 14.5 & 15660.8 & 250.2 & 15911.0 & 15410.6 \\
\hline 5000 & 355.1 & 0.8 & 355.9 & 354.3 & 65896.8 & 11277.7 & 77174.5 & 54619.1 \\
\hline 10000 & 712.4 & 1.4 & 713.8 & 711.0 & 380850.7 & 27381.0 & 408231.7 & 353469.7 \\
\hline
\end{tabular}

Nilai mean 0.0 pada Tabel 6.11 menunjukkan bahwa waktu proses berada di bawah 0 mili sekon, atau dalam hitungan mikro sekon. Beban komputasi belum terlihat dikala menggunakan 5 sampai 100 router. Perbedaan akan terlihat ketika menggunakan lebih dari 100 router.

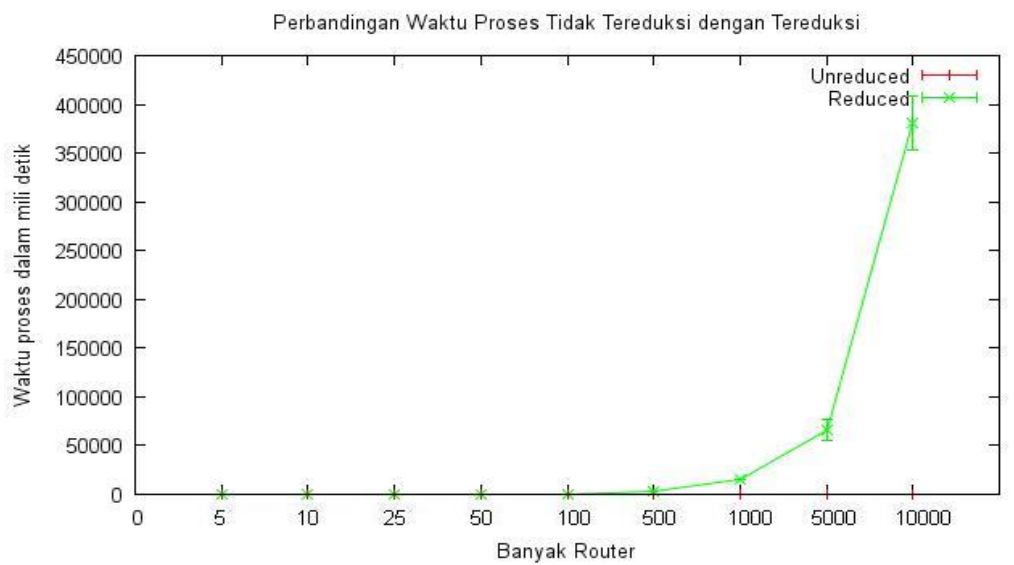

Gambar 3 Grafik error perbandingan waktu proses antara QoS tidak tereduksi dengan QoS tereduksi

Gambar 3 menunjukkan perbedaan waktu proses antara menggunakan proses reduksi dengan tidak menggunakan proses reduksi di mana pada gambar tersebut terlihat perbedaan yang drastis ketika percobaan menggunakan router diatas 500 router. Pada penggunaan router di bawah 500 router, terlihat waktu proses adalah 0 mili detik. Hal ini diasumsikan nilai 0 tersebut adalah nilai ketika waktu proses berada di bawah 0 mili detik atau dalam hitungan mikro detik. Hal ini merupakan keterbatasan aplikasi penghitungan waktu dalam bahasa pemrograman yang dipakai dalam penelitian ini.

Tabel 12 menunjukkan percobaan menggunakan 10000 router dengan topologi yang sama untuk setiap percobaannya. Topologi yang digunakan pada percobaan Tabel 12 dapat diunduh di alamat http:/goo.gl/iF6Vm. Percobaan menggunakan 20 pasang sumber dan tujuan dari router. Dimulai dari router 1 ke berbagai tujuan router yang dipilih secara acak. Tujuan dari percobaan ini adalah melihat perbedaan waktu komputasi dan bobot antara menggunakan reduksi dengan tidak menggunakan reduksi di mana waktu komputasi disini ditunjukkan oleh kolom $\mathrm{T}$ dengan satuan mili detik yang memiliki makna waktu komputasi adalah waktu yang diperlukan untuk menghasilkan sebuah rute dari sumber dan tujuan yang ditentukan.

IJCCS Vol. 6, No. 1, January 2012 : 79-90 
Tabel 12 Hasil percobaan menggunakan 10000 router pada topologi yang sama

\begin{tabular}{|c|c|c|c|c|c|c|c|}
\hline RUTE & \multicolumn{3}{|l|}{ UNREDUCED } & \multicolumn{3}{|l|}{ REDUCED } & PRMTR \\
\hline $\mathrm{KE}$ & RUTE & BOBOT & $\mathrm{T}$ & RUTE & BOBOT & $\mathrm{T}$ & Qos \\
\hline 1 & 1-5745-6754-6821-6498-6667-23 & 15217 & 715 & 1-2588-6904-6894-6998-6992-6799-6667-23 & 8676 & 392210 & $\mathrm{BJC}$ \\
\hline 2 & $1-5745-6754-6562-5463-3193-67$ & 13989 & 712 & 1-4169-5034-5671-5667-4708-2772-67 & 9192 & 389799 & $B J C$ \\
\hline 3 & 1-2588-6904-6921-6603-6715-5976-2315-89 & 17356 & 716 & 1-4169-1994-2896-3655-6715-6194-2315-89 & 8542 & 393128 & $B \mathrm{JC}$ \\
\hline 4 & 1-2588-6758-1344-4979-4413-4809-3304-103 & 14651 & 712 & 1-2588-6904-6894-6998-6992-7000-5260-2922-103 & 7143 & 400253 & $\mathrm{BJC}$ \\
\hline 5 & 1-2588-6758-6935-6949-6824-118 & 13145 & 712 & 1-2588-6904-6921-6935-6949-6824-118 & 7538 & 330875 & $\mathrm{BJC}$ \\
\hline 6 & 1-4169-5942-4008-4377-4228-4913-129 & 13300 & 713 & 1-2588-6904-6040-6696-6757-5725-129 & 8071 & 392210 & $\mathrm{BJC}$ \\
\hline 7 & 1-2588-6189-4339-4667-5190-5129-139 & 14147 & 715 & 1-2588-6904-6894-6998-6970-6597-139 & 7795 & 389742 & $\mathrm{BJC}$ \\
\hline 8 & 1-5745-6754-6821-6498-149 & 12269 & 718 & 1-4169-1994-2114-4112-2095-4253-149 & 7381 & 393157 & $\mathrm{BJC}$ \\
\hline 9 & 1-5745-6754-6765-5261-2701-159 & 14769 & 714 & 1-4169-5034-6993-6956-6329-5756-159 & 8337 & 425197 & $\mathrm{BJC}$ \\
\hline 10 & 1-2588-6904-6874-6665-6761-4520-169 & 14145 & 712 & 1-2588-6904-5460-6205-5419-169 & 7984 & 393128 & $\mathrm{BJC}$ \\
\hline 11 & 1-2588-6189-5613-6564-179 & 12649 & 710 & 1-2588-6904-6874-6665-5343-179 & 7911 & 425163 & $\mathrm{BJC}$ \\
\hline 12 & 1-5745-2416-6772-6221-189 & 14192 & 712 & 1-2588-6904-6365-6722-6801-189 & 7776 & 344780 & $\mathrm{BJC}$ \\
\hline 13 & 1-2588-6904-6914-6960-5184-1795-195 & 15765 & 715 & 1-5745-2416-1101-6066-1795-195 & 9163 & 353637 & $\mathrm{BJC}$ \\
\hline 14 & 1-2588-6904-6040-3114-5773-4447-207 & 13948 & 712 & 1-2588-6904-6365-6110-4038-207 & 7379 & 378574 & $\mathrm{BJC}$ \\
\hline 15 & 1-5745-6754-6562-5463-3886-4003-4097-434-217 & 16728 & 716 & 1-2588-6904-6894-6551-6460-5112-3528-217 & 8819 & 443018 & $\mathrm{BJC}$ \\
\hline 16 & 1-4169-5034-4434-6322-6161-221 & 15460 & 714 & 1-2588-6904-6040-6991-6982-2282-1653-221 & 8728 & 338983 & $\mathrm{BJC}$ \\
\hline 17 & 1-2588-6189-6788-6644-382-233 & 14530 & 713 & 1-5745-6619-6687-6930-2638-567-382-233 & 8298 & 397610 & $\mathrm{BJC}$ \\
\hline 18 & 1-2588-6904-6914-6827-5831-244 & 12744 & 713 & 1-5745-6754-6673-6789-5831-244 & 7260 & 389717 & $\mathrm{BJC}$ \\
\hline 19 & 1-4169-5942-6176-6182-5632 & 11444 & 713 & 1-2588-6904-6894-6551-6404-6436-3775-5632 & 8273 & 393438 & $\mathrm{BJC}$ \\
\hline 20 & 1-4169-5034-6993-6956-6954-6735-1732 & 14113 & 716 & 1-2588-6904-6894-6998-6999-6939-6735-1732 & 7266 & 425123 & $\mathrm{BJC}$ \\
\hline & AVG & 14228.05 & 713.65 & & 8076.6 & 389487.1 & \\
\hline & STDDEV & 1449.81 & 1.95 & & 640.43 & 29312.34 & \\
\hline
\end{tabular}

Tabel 13 Rata-rata dan standar deviasi terhadap bobot pada topologi yang sama

\begin{tabular}{|c|c|c|c|c|c|c|c|c|}
\hline Banyak & \multicolumn{4}{|c|}{ UNREDUCED } & \multicolumn{4}{c|}{ REDUCED } \\
\cline { 2 - 9 } Router & Mean & StdDev. & $\begin{array}{c}\text { Mean }+ \\
\text { StdDev }\end{array}$ & $\begin{array}{c}\text { Mean - } \\
\text { StdDev }\end{array}$ & Mean & StdDev & $\begin{array}{c}\text { Mean }+ \\
\text { StdDev }\end{array}$ & $\begin{array}{c}\text { Mean - } \\
\text { StdDev }\end{array}$ \\
\hline 10000 & 14228.05 & 1449.81 & 15677.9 & 12778.2 & 8076.6 & 640.43 & 8717.0 & 7436.2 \\
\hline
\end{tabular}

Tabel 13 menunjukkan rata-rata dan standar deviasi terhadap bobot antara menggunakan reduksi dengan tidak menggunakan reduksi. Hasil yang didapat adalah menggunakan reduksi menghasilkan bobot yang lebih kecil dibandingkan tidak menggunakan reduksi yaitu 8076.6 sedangkan tanpa reduksi, bobot yang dihasilkan adalah 14228.05.

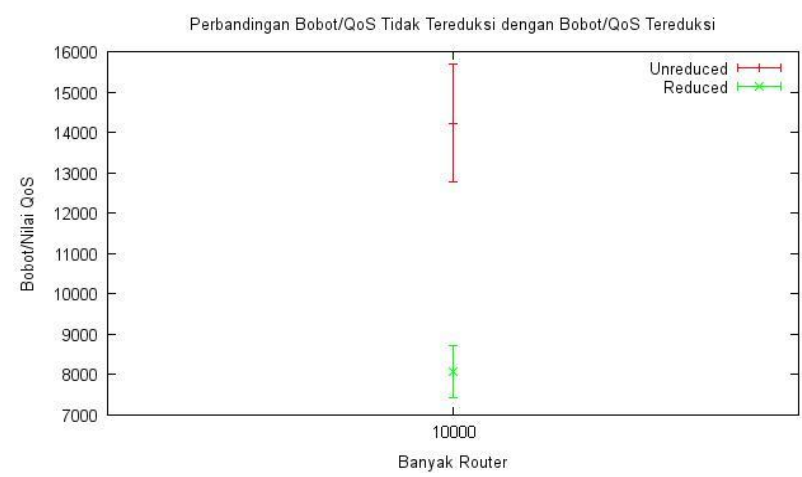

Gambar 4 Grafik error perbandingan bobot antara QoS tidak tereduksi dengan QoS tereduksi dalam topologi yang sama

Gambar 4 menunjukkan grafik error perbandingan bobot antara QoS tereduksi dengan QoS tereduksi di mana dalam grafik tersebut terlihat perbedaan yang sangat signifikan yang menunjukkan bahwa bobot yang dihasilkan dengan menggunakan proeses reduksi lebih kecil dibandingkan dengan tidak menggunakan reduksi sehingga proses reduksi dianggap perlu dilakukan untuk menghasilkan rute yang lebih baik.

Tabel 14 Rata-rata dan standar deviasi terhadap T pada topologi yang sama

\begin{tabular}{|c|c|c|c|c|c|c|c|c|}
\hline Banyak & \multicolumn{4}{|c|}{ UNREDUCED } & \multicolumn{4}{|c|}{ REDUCED } \\
\cline { 2 - 8 } Router & Mean & StdDev. & $\begin{array}{c}\text { Mean }+ \\
\text { StdDev }\end{array}$ & $\begin{array}{c}\text { Mean } \\
- \\
\text { StdDev }\end{array}$ & Mean & StdDev & $\begin{array}{c}\text { Mean + } \\
\text { StdDev }\end{array}$ & $\begin{array}{c}\text { Mean - } \\
\text { StdDev }\end{array}$ \\
\hline 10000 & 713.7 & 2.0 & 715.6 & 711.7 & 389487 & 29312.3 & 418799.4 & 360174.8 \\
\hline
\end{tabular}


Tabel 14 menunjukkan rata-rata dan standar deviasi terhadap $\mathrm{T}$ antara menggunakan reduksi dengan tidak menggunakan reduksi. Hasil yang didapat adalah menggunakan reduksi menghasilkan waktu komputasi yang lebih lama dibandingkan tidak menggunakan reduksi yaitu 389487 mili detik atau sekitar 6 menit sedangkan tanpa reduksi, waktu yang diperlukan adalah 713 mili detik.

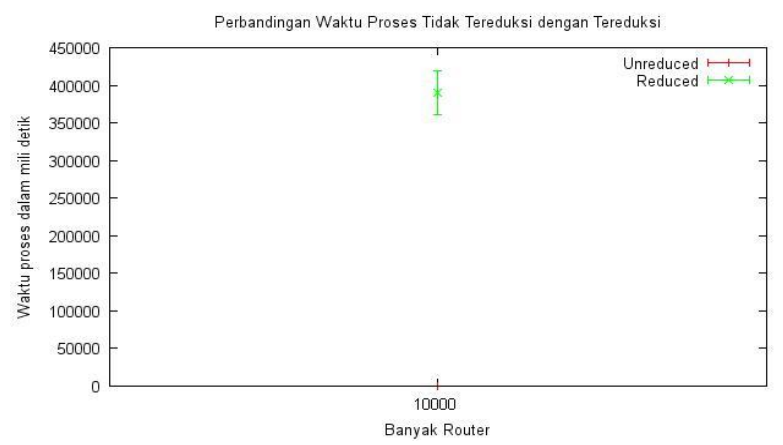

Gambar 5 Grafik error perbandingan waktu komputasi $(\mathrm{T})$ antara QoS tidak tereduksi dengan

QoS tereduksi dalam topologi yang sama

Gambar 5 menunjukkan grafik error perbandingan waktu komputasi antara QoS tereduksi dengan QoS tereduksi di mana dalam grafik tersebut terlihat perbedaan yang sangat signifikan yang menunjukkan bahwa waktu yang diperlukan dengan menggunakan proeses reduksi lebih lama dibandingkan dengan tidak menggunakan reduksi sehingga proses reduksi dianggap bermasalah dalam hal waktu komputasi.

Permasalahan komputasi disini dapat di atasi dengan menggunakan tabel routing ketika mekanisme penggunaan proses reduksi dilakukan

Tabel 15 Inisiasi awal tabel routing

\begin{tabular}{|c|c|c|}
\hline Tujuan & Rute & Bobot \\
\hline$\ldots$ & $\ldots$ & 15217 \\
\hline 23 & $(1-5745-6754-6821-6498-6667-23)^{\star}$ & $\ldots$ \\
\hline$\ldots$ & $\ldots$ & $\ldots$ \\
\hline$\left.{ }^{*}\right)$ Primary route & $\ldots$ & $\ldots$ \\
\hline
\end{tabular}

Tabel 15 diasumsikan dimiliki oleh router 1 . Tujuan dari router 1 adalah salah satunya ke router 23. Tabel 15 merujuk pada percobaan pertama pada Tabel 9 dan Tabel 12. Pertamatama proses yang berjalan adalah proses konvensional tanpa menggunakan proses reduksi yang memiliki waktu proses sangat cepat pada kondisi jaringan skala besar (10000 router). Hasil dari proses ini adalah rute dari router 1 ke router 23 yaitu 1-5745-6754-6821-6498-6667-23. Rute ini untuk sementara digunakan sebagai rute primer (primary route). Proses reduksi akan berjalan setelah inisiasi pertama tabel routing. Proses ini seperti mekanisme update routing table pada router-router pada umumnya sehingga akan menghasilkan tabel routing yang baru seperti pada Tabel 16.

Tabel 16 Tabel routing setelah proses update

\begin{tabular}{|c|c|c|}
\hline Tujuan & Rute & Bobot \\
\hline$\ldots$ & $\ldots$ & $\ldots$ \\
\hline & $(1-2588-6904-6894-6998-6992-6799-6667-23)^{*}$ & \\
23 & $(1-5745-6754-6821-6498-6667-23)$ & 15217 \\
& $\ldots$ & $\ldots$ \\
\hline$\ldots$ & $\ldots$ & \\
\hline \multicolumn{2}{|c|}{$\left({ }^{*}\right)$ Primary route }
\end{tabular}

Tabel 16 menunjukkan proses reduksi akan menghasilkan bobot dan rute yang berbeda dengan rute sebelumnya. Jika nilai bobotnya ternyata lebih kecil (baik), maka rute yang dihasilkan oleh proses reduksi yaitu rute 1-2588-6904-6894-6998-6992-6799-6667-23 akan menjadi rute primer menggantikan rute sebelumnya. Diharapkan dengan mekanisme tersebut, beban komputasi tidak akan dialami sehingga proses reduksi tetap dapat diaplikasikan.

IJCCS Vol. 6, No. 1, January 2012: 79-90 


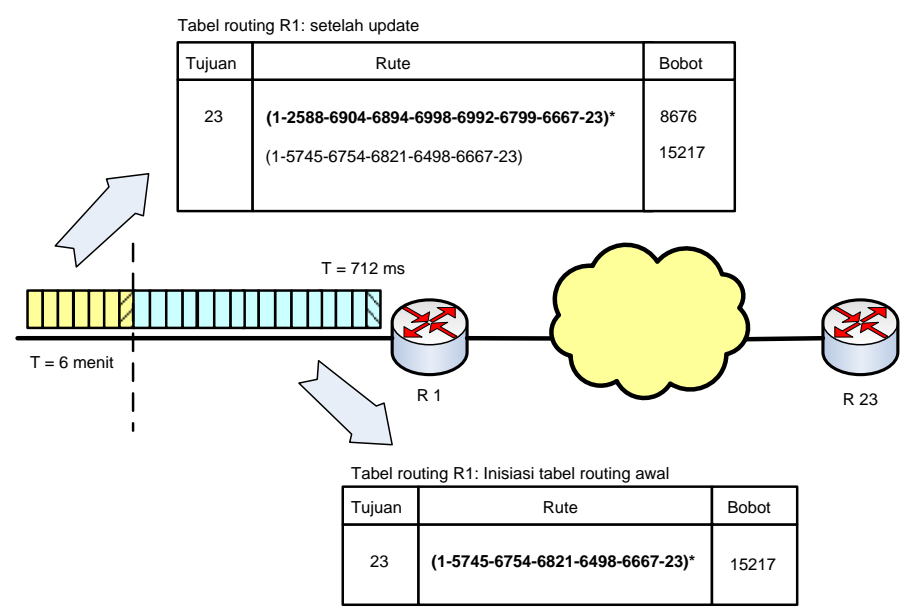

Gambar 6 Ilustrasi mekanisme tabel routing terhadap proses reduksi dalam jaringan

Gambar 6 menunjukkan ilustrasi mekanisme paket-paket data dalam jaringan berkaitan dengan tabel routing dan proses reduksi. Pada saat router pertama kali dioperasikan, router akan melakukan inisiasi tabel routing yang bertujuan menghasilkan rute-rute yang akan dilalui oleh paket yang mendatangi router tersebut. Paket yang pertama kali datang akan dilayani router dengan sangat cepat karena proses inisiasi tabel routing dilakukan tanpa menggunakan reduksi yang menurut percobaan pada Tabel 12 hanya membutuhkan waktu 713 mili detik. Setelah 713 mili detik, paket pertama tersebut akan di arahkan menggunakan rute yang telah dihasilkan yaitu 1-5745-6754-6821-6498-6667-23.

Sementara paket menggunakan rute pertama, update tabel routing dilakukan. Update tabel routing dilakukan menggunakan proses reduksi yang menurut percobaan Tabel 12 menghasilkan waktu sekitar 6 menit. Jadi, paket data pada saat menit ke-6 akan menggunakan rute yang baru yang didapat dari hasil proses update tabel routing yaitu rute 1-2588-6904-68946998-6992-6799-6667-23. Rute tersebut dinilai lebih baik karena memiliki nilai QoS (bobot) yang lebih kecil dibandingkan dengan rute sebelumnya. Hal ini ditunjukkan oleh Tabel 12 dan grafik pada Gambar 3.

\section{KESIMPULAN}

Kesimpulan yang diperoleh dalam penelitian reduksi parameter QoS dengan teori rough set dalam simulasi routing pada jaringan komputer menggunakan algoritma Dijkstra adalah:

1. Hasil penelitian pada Tabel 1 sampai dengan Tabel 9 menunjukkan bahwa parameter QoS dapat direduksi dengan teori RS sehingga memperoleh parameter QoS yang lebih sedikit sehingga akan menghasilkan jalur terbaik berdasarkan bobotnya pada topologi jaringan menggunakan algoritma Dijkstra.

2. Hasil penelitian pada Tabel 10 menunjukkan bahwa perbandingan kualitas bobot pada jalur routing antara menggunakan reduksi dengan tidak menggunakan reduksi sangat jauh. Hal ini ditegaskan pada grafik error Gambar 1 di mana penggunaan proses reduksi akan menghasilkan bobot yang lebih kecil (baik) dibandingkan dengan tidak menggunakan reduksi.

3. Beban komputasi yang dihasilkan oleh proses reduksi cukup lama yaitu sekitar 6 menit. Hal ini terlihat jika menggunakan 10000 router pada percobaan Tabel 9 dan Tabel 12 di mana jika tidak menggunakan proses reduksi hanya memakan waktu sekitar 713 mili detik. Namun hal tersebut dapat di atasi dengan mekanisme routing tabel dengan menempatkan proses reduksi pada level sekunder. Hasil yang didapat adalah grafik Gambar 3 untuk bobot dan Gambar 4 untuk waktu komputasi di mana ini menunjukkan inisiasi tabel routing dilakukan oleh proses tanpa reduksi. Proses tanpa reduksi dijalankan terlebih dahulu guna 
menutupi beban komputasi kemudian setelah itu dilakukan update tabel routing dengan menggunakan proses reduksi untuk menghasilkan rute yang baru sesuai dengan ilustrasi Gambar 5.

\section{SARAN}

Adapun saran-saran terhadap penelitian reduksi parameter QoS dengan teori rough set dalam simulasi routing menggunakan algoritma Dijkstra agar kedepannya penelitian ini lebih baik adalah:

1. Penelitian menggunakan data yang real, dalam artian menggunakan data topologi dan data nilai QoS berdasarkan data nyata seperti yang ada di lapangan.

2. Percobaan penelitian dilakukan pada objek nyata di lapangan bukan hanya simulasi semata.

Menambahkan metode pencarian heuristik pada proses reduksi parameter QoS dalam teori reduksi rough set seperti algoritma genetik agar hasilnya dapat dibandingkan dengan penelitian ini yang hanya menggunakan aljabar boolean sederhana pada proses reduksinya.

\section{UCAPAN TERIMA KASIH}

Penulis mengucapkan terima kasih kepada Bapak dan Ibu di rumah yang telah memberikan dukungan finansial selama penulis melakukan penelitian.

\section{DAFTAR PUSTAKA}

[1]Kurose, J., Ross, K., 2010, Computer Networking, Edisi Kelima, Addison-Wesley, Pearson Education, INC, Boston.

[2]Sakr, A.A., Kozae, A.M., Elshafae, M., Ibraheem, M.R., 2010, Optimizing Network Routing by Deducing a QoS Metric Using Rough Sets, International Journal of Engineering Science and Technology, Vol. 2(7), 3101-3110.

[3]Cisco-System, 2007, CCNA - Exploration 4: Routing Protocols and Concepts, Cisco Network Academy. California.

[4]Sarfraz, M., Javed, Y., Anjum, A., Sohail, S., 2010, Routing Optimization Strategy Using Genetic Algorithm Utilizing Bandwidth and Delay, IEEE, Vol. 4, 158-162.

[5]Khattab, S., 2009, An Intelligent Network Routing - Genetic Adaptive Routing Algorithm(Gara),http://www.just.edu.jo/ eyas/Index\%20Files/Algorithm_Shihab\%60s\%20K hattab\%20presentation.pdf, diakses tanggal 3 Juni 2011.

[6]Clement, B., 2006, Abstract Reasoning for Planning and Coordination, http://www.cs.cmu.edu/afs/cs/project/jair/pub/volume28/clement07ahtml/7_3Communication_Overhead.html, diakses pada tanggal 3 Juni 2011.

[7]Komorowski, J., Polkowski, L., Skowron, A., 1997, Rough Sets: A Tutorial, http://www.uit.edu.vn/forum/index.php?act=Attach\&type $=$ post\&id=19757, diakses tanggal 5 Juni 2011.

IJCCS Vol. 6, No. 1, January 2012 : 79-90 